\title{
msatico
}

\section{O desafio da}

educação popular

na luta pela

reforma urbana: $o$

exemplo do

Espaço Criarte

Mariana Crioula

(ECMC) na

Ocupação

Manuel Congo

(MNLM-RJ)

Laura Rêdes ${ }^{1}$

Vinícius Neves ${ }^{2}$

1 Mestre em Planejamento Urbano e Regional do Instituto de Pesquisa e Planejamento Urbano e Regional da Universidade Federal do Rio de Janeiro (IPPUR/UFRJ). E-mail: laura.redes1@gmail.com

2 Professor de ensino básico. E-mail: profviniciusneves@gmail.com

The challenges of Popular Education in the struggle for Urban Reform: the exemple of Espaço Criarte Mariana

Crioula at the Ocupation Manuel Congo 


\section{Resumo:}

O presente artigo discorrerá sobre a avaliação da prática pedagógica do Espaço Criarte Mariana Crioula na Ocupação Manuel Congo (RJ) na perspectiva da luta pela Reforma Urbana. Desta forma, pretendemos relacionar o tema da Reforma Urbana e da Educação Popular com as ações do Movimento Nacional de Luta pela Moradia do Rio de Janeiro (MNLM-RJ), especificamente sobre o processo da consolidação da Ocupação Manuel Congo e a construção do núcleo de educação popular Espaço Criarte Mariana Crioula.

Palavras-chave: Reforma Urbana, Educação Popular, Ocupação Manuel Congo, Espaço Criarte Mariana Crioula

\section{Abstract:}

The presente article discourses about the evaluation in the pedagogical practice of Espaço Criarte Mariana Crioula at the Ocupation Manuel Congo on the perspective of stuggle for the Urban Reform. Thus, we intend to relate the theme of Urban Reform and the Popular Education with the actions of the Movimento Nacional de Luta pela Moradia of Rio de Janeiro, specifically about the consolidation process of Ocupation Manuel Congo and the construction of the core of Popular Education at Espaço Criarte Mariana Crioula.

Keywords: Urban Reform, Popular Education, Ocupation Manuel Congo, Espaço Criarte Mariana Crioula. 


\section{O método de pesquisa}

Quando se realiza uma pesquisa vários questionamentos são colocados em jogo. Desde a escolha do tema até a trajetória que o estudo irá tomar, já é possível afirmar muito acerca sobre como o pesquisador pensa. Ou seja, o pesquisador, intelectual, acadêmico é ao mesmo tempo, um indivíduo que experimenta, vive na sociedade e está inserido em um contexto político, econômico e social. Nesse sentido, muitas vezes, não podemos colocar a ciência como algo dissociada da ação política. Com uma atuação que vai além da comunidade acadêmica, a relação entre pesquisador, ciência e sociedade se cruzam para a definição de problemas sociais que demandam ações e políticas estatais e não apenas a busca pelo monopólio do conhecimento (BATISTA, 2017). Para que isso aconteça é necessário que a autoridade do pesquisador seja retirada e traga contribuições importantes no campo das pesquisas qualitativas, sobretudo aquelas que tratam sobre processos que relatam desigualdades sociais. Com isso, o método etnográfico ${ }^{1}$ - ou a observação participante ${ }^{2}$ - se tornou o mais pertinente para o estudo, tendo em vista a inserção dos pesquisadores como militantes do Movimento Nacional de Luta por Moradia - RJ.

\section{Tanta casa sem gente, tanta gente sem casa: o processo de redemocratização e a luta pela Reforma Urbana ${ }^{3}$}

Desde 1960 a disputa por reformas estruturais na questão fundiária está presente no cenário político brasileiro, sobretudo a necessidade de uma Reforma Agrária. A questão de democratização da terra urbana emerge ainda nessa década, mas assim como a Reforma Agrária é inviabilizada pelo regime político autoritário de 1964.

Nos anos 80 os temas que envolvem a Reforma Urbana reaparecem nos discursos dos movimentos sociais em um contexto de luta pela redemocratização do país e de deslocamento da classe trabalhadora do campo para as cidades que cresciam a passos largos sem uma infraestrutura adequada ao crescimento populacional. Assim, no meio urbano afloravam situações de extrema segregação espacial, com bairros periféricos sem nenhum investimento público - carência de transporte, saneamento, escolas, hospitais, moradia etc. além da exploração dos trabalhadores nas indústrias das cidades brasileiras. Apesar das demandas terem sido expostas de forma mais sistemática e organizada desde o início dos

\footnotetext{
1 “(...) fazer etnografia implica em: 1) preocupar-se com uma análise holística ou dialética da cultura; 2) introduzir os atores sociais com uma participação ativa e dinâmica e modificadora das estruturas sociais; 3 ) preocupar-se em revelar as relações e interações significativas de modo a desenvolver a reflexividade sobre a ação de pesquisar, tanto pelo pesquisador quanto pelo pesquisado." (MATTOS, 2011, p.49).

2 "Etnografia é também conhecida como: observação participante, pesquisa interpretativa, pesquisa hermenêutica, dentre outras. Compreende o estudo pela observação direta e por um período de tempo, das formas costumeiras de viver de um grupo particular de pessoas: um grupo de pessoas associado de alguma maneira, uma unidade social representativa para estudo, seja ela formada por poucos ou muitos elementos (...)" (MATTOS, 2011, p. 51).

3 Nesse tópico, utilizamos como fonte o artigo de Nelson Saule Jr. e Karina Uzzo, publicado no site http://base.d-p-h.info/pt/fiches/dph/fiche-dph-8583.html. Acessado em 15 de maio de 2019.
} 
anos 80 , foi em meados dessa década que emerge um movimento em escala nacional pela Reforma Urbana articulando diversas entidades e atores sociais.

Para além da questão da moradia, a luta pela Reforma Urbana abarcava uma cidade para todos os trabalhadores que dela participavam, construíam e usufruíam. Para isso era preciso assumir a crítica à cidade mercantilizada ${ }^{4}$, dos lucros, da valorização imobiliária, da propriedade privada; a cidade dividida entre ricos e pobres, entre os que possuem acesso aos serviços públicos e os que não possuem.

Desta forma, as reivindicações feitas pelos movimentos de luta pela Reforma Urbana vão além das questões da democratização do solo urbano: elas espraiam para a necessidade de justiça social, participação popular na gestão das cidades - busca para acabar com a visão tecnocrática de construção do espaço urbano e, sobretudo, a relação entre "falta de desenvolvimento" e "justiça social" - e condições adequadas para o bem viver. Nesse sentido, o direito à cidade ${ }^{5}$ se resume na sua democratização, na qualidade de vida dos seus habitantes, no acesso à terra como meio de moradia e de subsistência, transporte público, saneamento, no combate às desigualdades sociais e no direito de ir e vir. É, portanto, a desmercantilização de todos os bens e serviços que são essenciais ao pleno desenvolvimento da vida, é o direito para todas e todos que construíram a cidade independente de suas capacidades de pagarem por ela.

Nesse contexto o conservadorismo que habitava o Congresso brasileiro considerava alguns instrumentos utilizados pela Reforma Urbana - o usucapião e a função social da propriedade privada - como ameaças à ordem social e ao pleno desenvolvimento do país. Apesar da disputa se acirrar, os movimentos sociais não recuaram e avançaram significativamente na questão da participação popular na gestão das cidades com a autonomia dos municípios, com os referendos, os plebiscitos, os conselhos e as consultas públicas.

Diversas conquistas no que diz respeito à política urbana ocorreram pós-constituinte de 1988 como a formação do Fórum Nacional de Reforma Urbana (FNRU) que emerge no intuito de pressionar o Congresso a regulamentar o capítulo da política urbana da Constituição Federal, culminando no Estatuto da Cidade em 2001 - onde são estabelecidas "normas de ordem pública e interesse social que regulam o uso da propriedade urbana em prol do bem coletivo, da segurança e do bem-estar dos cidadãos, bem como do equilíbrio

\footnotetext{
${ }^{4}$ A noção de cidade mercantilizada foi inspirada pela leitura do livro "A cidade do pensamento único: desmanchando consensos" de Otília Arantes, Carlos Vainer e Ermínia Maricato, sobretudo do capítulo "Pátria, empresa e mercadoria" onde é colocado o projeto do planejamento estratégico no meio urbano: "É a constatação da competição entre cidades, que autoriza a venda das cidades, o emprego do marketing urbano, a unificação autoritária e despolitizada dos citadinos (...)" (2000, p.99).

5 O direito à cidade é uma expressão inspirada no livro "O direito à cidade" de Henri Lefebvre, sobretudo pelo último capítulo "Teses sobre a cidade, o urbano e o urbanismo" (p. 137).
} 
ambiental" 6 - e no Fundo Nacional de Habitação de Interesse Social (FNHIS), cujos recursos são destinados a provisão de projetos de habitação de interesse social.

Apesar dos avanços de mobilização popular e institucionais para o provimento do direito à cidade, a luta pela manutenção e pelo contínuo avanço nas questões referentes à política urbana e justiça social são constantes e devem estar nas pautas dos movimentos sociais e da população em geral para uma vida de qualidade para toda classe trabalhadora que constrói constantemente o meio urbano.

\section{Remando contra a corrente: apontamentos sobre Educação Popular}

Em diversos contextos socioculturais, militantes e educadores do mundo inteiro construíram durante muitos anos ao lado de operários, de sem terras e de movimentos urbanos que lutavam pela libertação colonial, uma prática pedagógica de recusa ao modelo civilizatório capitalista e portadora de propostas educativas radicalmente novas (OLIVEIRA \& OLIVEIRA, 1985).

A educação popular nasce e se desenvolve como uma prática interessada, engajada com os interesses das classes populares (BETTO \& FREITE, 1986), sobretudo, em um contexto que o analfabetismo era alto para um país que estava em pleno processo de desenvolvimento. A necessidade de intervenção na realidade social diante desse cenário surgiu com a formulação de pressupostos teóricos e metodológicos nesse campo. Um dos intelectuais brasileiros que conseguiu entender esse momento e reunir as questões e os desejos dos oprimidos e transformá-los em uma bandeira de luta foi Paulo Freire. Nesse contexto, a alfabetização de adultos também foi essencial para a mobilização da questão da educação no país (PINI, 2012).

Para Freire (1984), a tarefa pedagógica enquanto ato político envolve um posicionamento do educador. Respeitar os saberes dos educandos e aprender com eles não significa que o educador não tenha uma concepção de verdade, mesmo que temporária; faz parte da educação convencer o educando de determinados valores políticos. 0 conhecimento de educador e educando possui elementos diferentes e originais e não são necessariamente excludentes; muito pelo contrário: podem ser complementares na construção de um novo conhecimento que supere os anteriores. Assim, vivemos o convencimento mútuo como uma vitória com e não uma vitória sobre as classes oprimidas.

Concordamos com Freire (1984) quando afirma "que é a prática que ajuíza o discurso" (p.13). O ponto de partida sempre será a prática social dos educandos e não o saber do educador. A teorização deve refletir a prática (quem são os educandos, o que fazem, o que sabem, o que vivem, o que querem, que desafios encontram) de forma a

\footnotetext{
${ }^{6}$ A lei que estabelece as diretrizes gerais da política urbana pode ser acessada através do site do Planalto por meio do link http://www.planalto.gov.br/ccivil 03/leis/leis 2001//10257.htm. Acessado em 15 de maio de 2019.
} 
instrumentalizá-la. Nesse sentido, a teoria não acrescenta nada ao real, mas o ilumina, permite compreendê-lo melhor e orienta a prática. Podemos então concluir que não é o discurso sobre a educação popular que tem caráter subversivo, mas sim a prática no cotidiano.

Elaboramos um esquema geral com as principais características da educação popular, assinalando algumas referências dessa perspectiva pedagógica:

1. A centralidade atribuída ao diálogo, à ética e democracia. A primeira palavra sempre está com as classes populares, tomando centralidade na construção do projeto educativo;

2. A Cultura das classes populares e sua prática, subjetividades e imaginários (percebido, concebido e vivido) são ao mesmo tempo o caminho e a caminhada de um horizonte emancipatório e a educação popular é um dos recursos de orientação em busca desse caminho em construção. (BRANDÃO, 1984).

3. Reconhecimento da prática de exercício da organização e da luta da vida cotidiana como espaço de aprendizagem;

4. A sistematização e reflexão constante da prática como elemento estruturante da práxis pedagógica.

Para nós, essas são as referências basilares da educação popular e é a partir desses elementos que refletiremos a prática realizada no Espaço Criarte Mariana Crioula (ECMC).

\section{"Com luta, com garra, a casa sai na marra" - a Ocupação Manuel Congo (MNLM- RJ) e o Espaço Criarte Mariana Crioula (ECMC)}

A decisão pela mobilização e organização para ocupar imóveis vazios em áreas infraestruturadas do centro do Rio de Janeiro pelo Movimento Nacional de Luta pela Moradia do Rio de Janeiro (MNLM-RJ) estava intimamente relacionada ao contexto mais abrangente da política nacional brasileira. A década dos anos 2000 foi marcada por uma forte institucionalização dos movimentos populares, fato que se intensificou com a eleição em 2002 de Luiz Inácio Lula da Silva, do Partido dos Trabalhadores (PT), para a presidência da república.

A eleição de um presidente de origem popular, com trajetória política vinculada à luta dos trabalhadores, que chegou a ser presidente de um dos principais sindicatos operários do Brasil, o Sindicato dos Metalúrgicos de São Bernardo do Campo e Diadema, através de um partido de esquerda com clara origem popular, provocou a abertura de espaços institucionais no governo federal para os movimentos populares. Estes acreditaram que era o momento de colocarem em prática todo o acúmulo construído ao longo de mais de vinte anos de lutas sociais. Com os movimentos urbanos não foi diferente. 
Deu-se início a uma mobilização para a construção de uma cogestão das cidades entre os movimentos populares e o governo federal. Para tais movimentos era o momento de consolidação do Sistema Nacional de Desenvolvimento Urbano (SNDU) e do Fundo Nacional de Habitação de Interesse Social (FNHIS) - um fundo destinado à requalificação e construção de moradias, voltado à população de baixa renda, e da implantação de infraestrutura urbana complementares aos programas habitacionais de interesse social. Além disso, era preciso aprovar e sancionar o Estatuto das Cidades e criar um órgão federal capaz de articular as demandas dos movimentos e que estivesse preocupado com a elaboração de políticas urbanas.

Nesse contexto, que em 2003, foi realizada a I Conferência Nacional das Cidades com participação dos movimentos populares (União Nacional por Moradia, Central dos Movimentos Populares - CMP, Movimento Nacional de Luta Pela Moradia - MNLM, entre outros) estabelecendo um amplo debate com significativos avanços para a luta urbana, como a criação do Ministério das Cidades e a indicação de Olívio Dutra como Ministro da pasta, um antigo militante dos movimentos urbanos e um dos fundadores do MNLM.

Já em 2005 na II Conferência Nacional das Cidades, de acordo com a avaliação da coordenação estadual do MNLM, não foi feito uma boa avaliação da primeira conferência e pouca coisa do que foi acumulado foi posta em prática nos anos subsequentes. É preciso, mais uma vez, relacionar a luta urbana no Rio de Janeiro à conjuntura política nacional. Foi neste mesmo ano que escândalos de corrupção assolaram o alto escalão do governo petista. O pagamento de propina a parlamentares, conhecido como "mensalão", garantia ao palácio do planalto a maioria no parlamento em votações consideradas prioritárias, o que viabilizava um governo sem grandes barganhas por cargos executivos em troca do apoio no parlamento em nome da "governabilidade".

Tal situação teve consequências significativas para o Ministério das Cidades. Olívio Dutra, antigo militante popular e sindicalista, foi substituído pelo diplomata Marcio Fortes e, segundo a avaliação estadual do MNLM, os avanços vislumbrados na I Conferência Nacional das Cidades passaram a fazer parte do passado. Nesse sentido, uma importante parcela da liderança do MNLM chega à conclusão de que foi demasiado contemporizadora com a política do governo federal e que era preciso voltar a estabelecer um maior diálogo com a base e realizar atividades de rua.

Em 2006, longe de ser um consenso entre as lideranças do MNLM, a opção pela organização de famílias e militantes para ocupar imóveis na área central da cidade foi vitoriosa em relação à mobilização para escolher delegados para a III Conferência Nacional das Cidades. Todavia, a retirada do MNLM-RJ da conferencia não significa o total afastamento da via institucional: foi feita a avaliação de que seria através da mobilização e de atividades de rua que o movimento poderia acumular experiências e força política para avançar qualitativamente na política institucional partindo de outro patamar: o do retorno à mobilização e organização das classes populares. 
O primeiro passo dado para a mudança da linha de ação política da via institucional consensual para atividades de rua foi estabelecer uma estratégia para ocupação que estivesse vinculada aos acúmulos feitos em direção à construção da Reforma Urbana. Dentre os eixos estratégicos, se destacavam:

- Ocupação de imóveis vazios, especialmente públicos, a fim de denunciar o enorme estoque de terras voltado para especulação fundiária no Brasil que não cumpria nenhuma função social;

- Ocupação de áreas infraestruturadas das cidades - preferencialmente os centros urbanos - denunciando o espraiamento urbano com o deslocamento dos mais pobres para as periferias das cidades, causando sérios impactos sociais e ambientais derivados da falta de infraestrutura;

- Promoção à integração entre trabalho, moradia e construção do sujeito coletivo com autonomia sobre a gestão do território.

O segundo passo foi encontrar imóveis vazios na cidade, além de encontrar parceiros nas lutas do MNLM que ajudassem a mobilizar as famílias. As reuniões eram mensais e todas as famílias que participavam se enquadravam dentro dos critérios relacionados ao déficit habitacional quantitativo e qualitativo. Em outras palavras, segundo a metodologia da Fundação João Pinheiro (MINISTÉRIO DAS CIDADES, 2011), o déficit habitacional (quantitativo) está relacionado à população que vive em habitações precárias, coabitação familiar, com ônus excessivo no aluguel e ao alto adensamento de moradores em domicílios alugados. Já a inadequação dos domicílios (déficit qualitativo), segundo a mesma fundação, estende-se aos domicílios com carência de serviços de infraestrutura (energia elétrica, esgotamento sanitário, abastecimento de água, coleta de lixo), inadequação fundiária urbana, inexistência de unidade sanitária domiciliar exclusiva, cobertura inadequada e o alto adensamento de moradores em domicílios próprios. Acrescenta-se a esses critérios a avaliação da vida cotidiana das famílias, como, por exemplo, a residência próxima a áreas controladas por facções criminosas e de conflito deflagrado.

Ademais, devido a parâmetros impostos pela política pública de habitação de interesse social, todas as famílias deveriam possuir renda familiar de 0 a 3 salários mínimos. Tal critério justifica-se pela grande concentração do déficit habitacional nesta faixa, correspondendo a $83,9 \%$ do déficit habitacional brasileiro ${ }^{7}$. Por outro lado, tal parâmetro quantitativo nacional é limitador, principalmente no que diz respeito ao atendimento do déficit qualitativo, pois não considera as discrepâncias regionais sobre o custo de vida e ao valor da terra. $O$ déficit habitacional brasileiro, de acordo com os dados da Pesquisa Nacional

\footnotetext{
7 Os dados foram retirados do site da Câmara Brasileira de Indústria e Construção através do link http://www.cbicdados.com.br/menu/deficit-habitacional/deficit-habitacional-no-brasil. Acessado em 16 de maio de 2019.
} 
por Amostra de Domicílios (PNAD)-IBGE ${ }^{8}$ chega a mais de 6,355 milhões de domicílios, ao passo que até 2008 a quantidade de imóveis vagos nas áreas urbanas chegou a 5 milhões ${ }^{9}$. Grande parte desses imóveis vagos localiza-se em áreas urbanizadas que gozam de uma mínima infraestrutura urbana, em geral nas áreas centrais e consolidadas das grandes cidades, como no Rio de Janeiro, que conta com uma taxa de vacância de mais de $10 \%$ em todo município, sendo esse número maior na AP1 (Área de Planejamento 1) que engloba o centro da cidade, chegando a mais de $13 \%$ dos imóveis, cerca de $6,3 \%$ de todos os domicílios vagos na cidade (BIASOTTO, 2009). Esses dados serviram de base para a estratégia do MNLM-RJ de denúncia aos imóveis urbanos vazios, de ocupação desses imóveis e a sua destinação à habitação de interesse social. Nesse sentido, as reuniões que precederam a ocupação tinham como objetivo central a construção de um projeto coletivo.

A metodologia consistia em levar as famílias a pensar criticamente o seu local de moradia, o que gostavam e o que não gostavam, o que poderiam fazer para mudar e o que gostariam que fosse diferente no lugar para onde iriam. Foram realizadas dinâmicas de grupos, músicas, poesias, textos, relatos de experiência, atividades de trabalho coletivo, a fim de mobilizar, integrar os futuros ocupantes e construir uma carta de princípios. Também foram organizadas brigadas de infraestrutura, segurança, alimentação e escolhido o nome da ocupação: Manuel Congo. Tudo foi discutido coletivamente com a orientação da coordenação estadual do MNLM.

Segundo alguns entrevistados ${ }^{10}$, foi criado um clima de forte empolgação entre as famílias à medida que se aproximava o dia da ocupação. A seleção do imóvel era tarefa da coordenação; por questões de segurança, as famílias que estavam sendo preparadas só conheceram o local da ocupação no dia da entrada no imóvel. Para identificação dos imóveis vazios realizavam-se atividades coletivas e "vaquinhas" para levantar recursos e pagar as certidões de ônus reais.

Dentre os diversos imóveis identificados, destacaram-se dois prédios, um público e outro privado, nas imediações da Cinelândia no centro da cidade do Rio de Janeiro. A área foi escolhida por ser um polo histórico cultural da cidade com prédios importantes como a Biblioteca Nacional, Teatro Municipal, Centro Cultural da Justiça Federal e Cinema Odeon, e estar próximo de uma das maiores áreas de lazer ao ar livre da cidade, o Aterro do Flamengo e junto à principal rua do centro, a Avenida Rio Branco. Sendo assim, ocupar prédios na

\footnotetext{
${ }^{8}$ Os dados foram igualmente retirados do site da Câmara Brasileira de Indústria e Construção através do link http://www.cbicdados.com.br/menu/deficit-habitacional/deficit-habitacional-no-brasil. Acessado em $16 \mathrm{de}$ maio de 2019.

${ }^{9}$ Informação retirada através do site do IPEA pelo link http://www.ipea.gov.br/desafios/index.php?option=com content\&view=article\&id=998: catid=28\&ltemid=23 Acessado em 20 de junho de 2019.

10 Uma atual moradora da ocupação Manuel Congo nos contou que todos estavam muito agitados para ocupar: "a gente sentia uma mistura de ansiedade e medo. Era algo imprevisível ocupar um imóvel, mas a possibilidade de realizar o sonho de ter a própria casa e ter acesso a transporte, lazer, saúde e educação, nos dava muita coragem". Outro morador nos falou a respeito da organização: "era tudo bem esquematizado, organizado. Os horários das reuniões, a participação das famílias nas atividades. Todos estavam muito comprometidos".
} 
Cinelândia significou abrir possibilidades de conjugar moradia, trabalho e lazer em uma mesma ocupação.

A escolha do Cine Vitória envolveu diversas questões; dentre elas destacou-se a importância cultural do imóvel. Construído na década de 1940, o suntuoso cinema foi durante muito tempo um dos maiores cinemas da América Latina, marcando de forma indelével, o universo cultural carioca. Além desse fator, os anos de ociosidade do imóvel (mais de dez anos à época da ocupação) incomodavam os diversos militantes do MNLM-RJ.

Outra questão igualmente importante foi a projeção que a ocupação de um imóvel privado poderia dar às lutas urbanas no Rio de Janeiro. O MNLM-RJ acreditava que o ataque direto à propriedade privada abalaria de forma mais contundente as estruturas da sociedade, podendo oferecer maior visibilidade às denúncias sobre o descumprimento do Estatuto das Cidades, que oferecia uma série de instrumentos para que imóveis como o Cine Vitória fossem requalificados e transformados em moradia de interesse social.

As perspectivas de repercussão da ocupação como previra o MNLM-RJ se confirmaram: o caso foi tratado pelo próprio Comandante Geral da Polícia Militar, o Coronel Ubiratan Ângelo, e pelo Governador do Estado, Sergio Cabral Filho. A resistência durou 8 dias e graças aos esforços das lideranças do MNLM-RJ, a fibra e tenacidade das famílias buscou-se o entendimento de uma solução pacífica junto com o comandante, à revelia da vontade do governador.

No dia 8 de outubro deu-se início a uma longa peregrinação das famílias. Despejados do Cine Vitória, seguiram imediatamente em direção à Secretaria Estadual de Habitação a fim de pressionar o Estado a oferecer uma solução em curto prazo para alojamento. Sem avançar nas negociações, a coordenação decide ocupar outro imóvel vazio, na Rua Regente Feijó, para as famílias passarem a noite. Escoltados pela polícia, os militantes seguem até a Praça Tiradentes próxima ao prédio de destino. Simultaneamente, a coordenação e parceiros de diversos movimentos sociais dão andamento, junto à Secretaria de Patrimônio da União (SPU), ao processo de negociação para a compra do prédio do INSS no número 20 da Rua Alcindo Guanabara. O processo é lento e novamente as famílias são despejadas. Como combinado, ocorreu uma nova mobilização para ocupar o então prédio de número 20 da Alcindo Guanabara. Mais uma vez a ocupação foi bem sucedida, só que dessa vez em um imóvel público federal. As negociações passaram diretamente à instância federal com a SPU e com o INSS. Todavia, a Superintendência Estadual do INSS entrara com o pedido de reintegração de posse do imóvel. Com o iminente despejo, o MNLM-RJ decide ocupar a III Conferência Estadual das cidades realizada nos dias 19, 20 e 21 de outubro de 2007, na Universidade do Estado do Rio de Janeiro (UERJ), denunciando a sua situação para os delegados estaduais dos demais movimentos urbanos, ONGs e organizações sindicais. $O$ secretário de habitação do estado presente na conferência se aproveita politicamente do ato, se aproxima do movimento, se oferece para fazer a interlocução com o INSS e estabelece contato direto com o Diretor Nacional do Departamento de Logística e Patrimônio do órgão, que logo se demonstra disposto a avançar com as negociações. Quando o juiz responsável decretou a reintegração de posse do prédio, deliberou também 
que seria necessária uma infraestrutura para o despejo das famílias - caminhões para levar os pertences, o que necessitaria da liberação de recursos da gestão central do INSS, que por sua vez alegou não ter verba para tal ação, demonstrando um claro racha entre a direção nacional do órgão e a superintendência do Rio de Janeiro. Esse processo foi fundamental para que o MNLM-RJ ganhasse tempo - cerca de 2 meses - para buscar novos aliados institucionais e promover novas mobilizações de rua que pudessem acelerar o processo de compra do prédio, evitando, assim, o despejo das famílias.

Na Conferência Nacional das Cidades realizada entre os dias 25 e 29 de novembro de 2007, a liderança nacional do MNLM articulada com diversos membros do Conselho Nacional de Reforma Urbana, entregou uma carta ao presidente da república, à época Luiz Inácio Lula da Silva, relatando a situação da ocupação Manuel Congo. Como era forte a mobilização política dos movimentos sociais em torno da ocupação, o presidente se compromete pessoalmente com a resolução do problema. As ações não pararam. No final do mesmo mês, dia 30, no lançamento do Projeto do Programa de Aceleração do Crescimento (PAC) na comunidade do Cantagalo, mais uma vez o MNLM-RJ organiza um ato exigindo a manutenção das famílias da Manuel Congo no prédio e a imediata liberação de recursos do FNHIS para a compra do mesmo junto ao INSS. É entregue mais uma carta ao Presidente da República, indicando a liberação dos recursos do FNHIS para a compra do imóvel pelo Estado via Instituto de Terras e Cartografia do Estado do Rio de Janeiro (ITERJ).

Somente 4 anos após a ocupação, o prédio de número 20 da Rua Alcindo Guanabara foi comprado pelo Estado do Rio de Janeiro junto ao INSS com recursos do FNHIS, a fim de destiná-lo à habitação de interesse social. O momento foi comemorado com a ocupação da sede da Caixa Econômica Federal no Rio de Janeiro, Agente Operador da Política Habitacional e dos investimentos sociais urbanos do Governo Federal. Todo esse processo de mobilização pela conquista do imóvel foi acompanhado da construção e organização do espaço coletivo da ocupação. Como um dos militantes do MNLM-RJ definiu, "no começo ficamos todos juntos como uma grande família". Foram organizados mutirões e brigadas para a criação da cozinha coletiva, cuidados com a infraestrutura do prédio (luz, água, etc), zelo pela segurança com o estabelecimento de turnos na portaria do prédio, além de um grupo de mulheres para tomar conta das crianças enquanto os pais realizavam as tarefas coletivas.

A preparação para a obra também foi um momento de grande importância para a mobilização das famílias em torno do projeto coletivo. Tinha-se a consciência de que os recursos do PAC/FNHIS ou do Minha Casa Minha Vida - Entidades, destinados à requalificação eram muito baixos e que deveria ser construída uma proposta criativa de modo que garantissem a manutenção dos espaços coletivos e pudesse, ao mesmo tempo, produzir habitações próximas do que cada família havia imaginado. Foram diversas atividades e discussões até chegar ao resultado final.

Outro processo central para o MNLM-RJ é a construção do projeto de autogestão que possibilite a junção da habitação com trabalho, em local infraestruturado com garantia 
de mobilidade e auto-organizado para emancipação. Desde o processo de preparação para a ocupação, o MNLM-RJ se preocupa em articular cultura, trabalho e moradia. O projeto começou a ser elaborado em 2006 pela coordenação com o estudo das expressões culturais populares, passando pela participação de todos que gostariam de trabalhar através de atividades que diagnosticassem os interesses, potencialidades e afinidades dos moradores.

Várias limitações com relação às políticas públicas foram superadas durante o processo. A Ocupação Manuel Congo e a ação do MNLM-RJ foram e são marcos nas lutas urbanas no Rio de Janeiro, seja pela localização do prédio no centro da cidade ao lado da Câmara dos Vereadores ou pelo pioneirismo na utilização do FNHIS para a compra de imóveis, na busca por financiamento para geração de renda e sustentabilidade do imóvel vinculado ao PTTS exigido pela Caixa e de ser o primeiro a realizar obras com a manutenção das famílias no imóvel. Nesse sentido, há indícios de que a avaliação feita pela coordenação do MNLM-RJ no final da II Conferência Nacional das Cidades foi sendo paulatinamente concretizada. A mobilização popular de rua proporcionou ao MNLM-RJ galgar novas conquistas institucionais para demandas dos movimentos urbanos, o que pode ser comprovado pela Ocupação Manuel Congo.

Hoje, a gestão coletiva do espaço continua sendo um dos princípios fundamentais que regem a ocupação. Existem espaços de uso coletivo como a sala da Assembleia - esta realizada uma vez por mês como instância deliberativa da ocupação -, a sala do Espaço Criarte Mariana Crioula (em processo de reconstrução) - núcleo de educação popular para as crianças e adolescentes da ocupação - a "casa de samba" - onde são realizados eventos e comemorações. A portaria e a limpeza ainda funcionam por meio de turnos. Há também a comissão de obras, responsável pela manutenção do prédio e pelo planejamento/acompanhamento da obra de requalificação do mesmo.

Um dos núcleos do MNLM com atuação mais presente na ocupação Manuel Congo é o coletivo de Pedagogia e Formação Política no Espaço Criarte Mariana Crioula. A preocupação com a educação de crianças e jovens foi um dos pilares da carta de princípios construída pela comunidade, apenas restava saber como e quem seria capaz de por em prática tais princípios. Foi assim que, no segundo semestre de 2008 , iniciou uma organização para a implementação de um espaço de educação para as crianças, diferente da pequena creche organizada para que os pais pudessem participar das atividades coletivas. Este espaço nascia com a proposta de pensar a educação popular no contexto da cidade.

No início eram atividades preocupadas com o reforço escolar e com a convivência das crianças naquele espaço coletivo que estava sendo construído. Hoje, o Espaço Criarte Mariana Crioula já conta na sua história com a participação de diversos educadores populares comprometidos com a transformação da sociedade; há uma cartilha de princípios pedagógicos do Espaço e são realizadas atividades duas vezes na semana, conciliando o reforço escolar com atividades lúdicas que estimulem a criatividade das crianças e jovens e, que possibilitem, através de múltiplas experiências, que esses estabeleçam consciência de si e de sua inserção no mundo. 
O desenvolvimento das crianças e adolescentes sempre foi uma preocupação dos militantes do MNLM. A necessidade de integrar a Educação Popular com a luta pela Reforma Urbana é um importante horizonte de combate e é desse desafio que nasce o Espaço Criarte Mariana Crioula na Ocupação Manuel Congo. Nesse sentido, o ECMC tem dois pontos de partida: surge da urgência de ter um espaço para pensar, propor e executar ações voltadas para as crianças e adolescentes das ocupações construídas pelo MNLM $^{11}$ e, vinculada a essa necessidade, está a construção e gestão coletiva da comunidade, o que passa pela compreensão de que todos são responsáveis pelo pleno desenvolvimento dos indivíduos do grupo, principalmente as crianças. Sendo assim, era e é fundamental que o MNLM criasse e crie mecanismos, espaços e atividades que possibilitem a edificação de uma proposta de educação coletiva, vinculadas aos seus princípios e suas práticas.

No processo de construção de um espaço pedagógico para a Ocupação Manuel Congo, a direção do MNLM buscou desde seu início o diálogo com professores e estudantes de pedagogia da Universidade Estadual do Rio de Janeiro, no sentindo de construir uma parceria com o MNLM para elaborar e realizar atividades voltadas para alfabetização das crianças da Ocupação. Contudo, o projeto não se consolidou, pois havia uma dificuldade de enquadrar a agenda da academia às necessidades do movimento e, ainda, era necessário que militantes do MNLM, principalmente moradores da ocupação, participassem da construção de qualquer projeto pedagógico que fosse ser implementado.

No segundo semestre de 2008, a iniciativa tão sonhada começa a tomar contorno. Uma das militantes mais antigas do MNLM, que havia participado de inúmeras experiências no campo da educação popular, iniciou as atividades com aulas de reforço para as crianças do primeiro seguimento do ensino fundamental. Entretanto, entendia-se que não se tratava apenas de criar uma extensão da escola formal, mas atender às demandas políticas do MNLM e do cotidiano da comunidade. Logo, são incorporadas atividades lúdicas vinculadas à construção do sujeito coletivo, à perspectiva revolucionária da classe trabalhadora, aos princípios do movimento e à luta pela Reforma Urbana.

Outra questão importante é o fato do ECMC fazer parte de um movimento popular. Tal fato vincula a experiência pedagógica às necessidades que extrapolam a relação entre educandos e educadores, pois está comprometida com a Reforma Urbana e a transformação da sociedade vigente. É uma experiência educacional para além da qualificação para a atividade laborativa: vincula-se à vida política e militante, formando crianças para que se tornem politicamente conscientes da cidade em que vivem, do papel que cumprem e podem cumprir na sociedade.

Um dos adolescentes que frequentava o ECMC desde o início das atividades tinha uma visão interessante acerca das semelhanças e diferenças do Espaço em relação à escola formal: "há diferença em tudo. Só não muda é que vocês ajudam em deveres e passam

\footnotetext{
${ }^{11}$ A Ocupação Mariana Crioula, na Gamboa e a Ocupação Solano Trindade em Duque de Caxias (ambas do MNLM) também estavam dentro do projeto do ECMC.
} 
deveres porque de resto é bem diferente. Ambiente, modo de ensinar, modo de ajudar, modo de brincar, a gente sai quase todo fim de semana!". Pais e mães, em geral, não têm uma concepção tão abrangente das especificidades do ECMC em relação à escola formal. Em entrevista, uma das mães de crianças que frequentavam o ECMC, chegou a mencionar que não havia diferença entre tais espaços: "são feitas atividades da mesma forma que na escola". Porém, com perguntas mais específicas relacionadas à possibilidade de participação dos pais, foi percebendo algumas variantes significativas, chegando a mencionar o fato de todos os seus filhos frequentarem o mesmo espaço, independente da série na escola, o que acabava facilitando o acompanhamento feito por eles.

O caráter multisseriado é outra característica importante da estrutura de funcionamento do Criarte. As atividades são pensadas e realizadas para dois grupos distintos, sendo que, diferentemente da escola formal, a separação dos grupos não é feita a partir do nivelamento de conteúdo adquirido pelas crianças, muito pelo contrário: compartilhar experiências e conhecimento através da ajuda mútua é um dos pilares da prática pedagógica do ECMC. Os grupos são divididos por faixa etária e, desse modo, avaliase que há um descompasso entre os interesses dos mais novos e dos mais velhos. Sendo assim, para dar conta das demandas específicas, os horários das atividades são divididos. Os mais novos (de 2 a 9 anos) iniciam as atividades mais cedo e, em seguida, os mais velhos (10 a 16 anos).

Apesar desses elementos alguns responsáveis seguiam compreendendo o ECMC como expansão da escola formal ou, até mesmo, recreação. Isso dificultou e dificulta a participação e a construção coletiva do projeto pedagógico, uma vez que a escola tradicional é marcada pela divisão e hierarquização do trabalho, no qual um grupo de especialistas "pensa" e planeja e outro executa. Podemos citar também a relação clientelista com os responsáveis pelas crianças, que recebem a educação dos seus filhos como um produto fechado, sem que haja a possibilidade da participação no planejamento e gestão do espaço escolar. Para entendermos esse processo é mister buscar compreender as relações de poder no âmbito da educação popular ${ }^{12}$. Para Garcia (1984), estas relações encontram-se em dois níveis: na disputa política no âmbito da totalidade da sociedade; e no interior da prática educacional, na relação educador/grupos populares.

Sobre o primeiro, entendemos que em uma sociedade de classes, os saberes e o conhecimento da classe dominante são os saberes e conhecimentos dominantes. Isso significa que toda e qualquer proposta de educação que valorize o conhecimento e saberes originários das classes subalternas tem caráter contra hegemônico. Ademais, não podemos conceber o saber dominante e dominado como se fossem isolados e independentes um do outro. São faces da mesma moeda, produto de uma sociedade de classes sociais antagônicas e o saber é uma das dimensões da luta de classes (GARCIA,1984).

\footnotetext{
${ }^{12}$ A relação de poder perpassa pela ausência de participação dos responsáveis tendo em vista a crença de que os educadores/militantes detém o conhecimento necessário a serem transmitidos para os seus filhos.
} 
Para ser coerente com a proposta pedagógica libertadora que se propõe é fundamental superar esse sistema de poder e estabelecer uma prática que reforce o poder das camadas populares, partindo de seus interesses e estimulando o seu protagonismo na construção do projeto pedagógico.

Desse modo, a prática é a flecha norteadora das atividades desenvolvidas no ECMC. Os princípios foram construídos a partir da reflexão da prática cotidiana aliada a um olhar teoricamente informado, vinculado à tradição da educação libertadora, das lutas da classe trabalhadora. A metodologia foi construída a partir da relação com as crianças, com as concepções e princípios do MNLM, da luta pela Reforma Urbana e das necessidades mais imediatas da comunidade.

Se a realidade é sempre o ponto de partida da educação popular, tantas serão as práticas e métodos quantos serão as realidades socioespaciais em que se desenvolverá tal processo. Nas palavras de Brandão (1984, p. 129), "não há métodos nem sistemas pedagógicos rígidos, porque é cada passo da prática política que dita as regras de nossa didática".

É preciso dizer que não acreditamos em um messianismo do saber e da cultura popular. Tanto o educador quanto as classes populares reproduzem a ideologia dominante; não se trata de uma inversão: a verdade agora passa aos grupos populares e o educador passa a ser o portador da ideologia dominante. Mais uma vez vale ressaltar o caráter dialógico da educação popular, em que cada grupo e cada educador devem estar abertos a reinventar e reavaliar os seus conhecimentos.

\section{Considerações Finais}

Neste trabalho nos dispomos a analisar a prática pedagógica desenvolvida no Espaço Criarte Mariana Crioula (ECMC), na relação determinada/determinante face à produção do espaço da Ocupação Manuel Congo. Compreendemos que tal prática está condicionada por determinadas conjunturas espaço-temporais, sincrônica e diacronicamente. Isso quer dizer que as práticas hoje desenvolvidas são resultado de um longo processo civilizatório, vinculado à modernidade, ao surgimento e difusão do modo de produção capitalista e ao modelo de desenvolvimento a ele relacionado. Mas também está ligado a temporalidades de atores sociais diversos (movimento popular, Estado, grandes corporações, rentistas e especuladores fundiários, etc.) que ao mesmo tempo configuram uma realidade socioespacial específica, de ação multi e transescalar.

A Ocupação Manuel Congo é ao mesmo tempo produto e reação do modelo de desenvolvimento hegemônico da cidade mercadoria. É produto como resultado da precarização da vida urbana (déficit habitacional, problemas relacionados à (i)mobilidade urbana, violência, etc.), fruto de um modelo de cidade cada vez mais voltado para a reprodução ampliada de capital, no qual o próprio espaço urbano torna-se uma das 
mercadorias privilegiadas do atual processo de acumulação. Também é reação quando algumas centenas de trabalhadores urbanos resolvem tomar protagonismo de suas vidas, mesmo que por alguns momentos, e se incorporam a um projeto coletivo e ocupam um espaço que, dentro da ordem estabelecida, não deveria ser apropriado por eles.

Evidentemente o processo de luta e resistência que resulta na Ocupação não se resume aos seus moradores. Está inserido numa estratégia mais ampla da luta da classe trabalhadora, em um movimento popular de abrangência nacional, o Movimento Nacional de Luta pela Moradia, que busca em sua missão conciliar as demandas mais imediatas da classe trabalhadora e um horizonte de superação radical da sociedade capitalista. Entendemos que essa dupla missão é construída dentro das ocupações do MNLM, atrelando a construção de espaços de autonomia, onde há o estímulo e valorização do sujeito coletivo, à luta mais ampla pela Reforma Urbana e pelo direito à cidade.

É nesse contexto que surge o ECMC como proposta de construção de um projeto pedagógico coletivo, no qual se compreende os indivíduos da comunidade como responsabilidade de todos, principalmente as crianças e adolescentes. Compreendemos a prática pedagógica do ECMC como um instrumento de construção do espaço vivido, no qual o indivíduo possa sair do automatismo da concepção hegemônica e construa uma consciência que possibilite a resistência e a transformação.

Dentre os desafios do ECMC (e porque não de todo o MNLM?) está o de construir as bases de edificação do poder popular, onde os indivíduos das classes populares possam ser protagonistas de suas vidas. Nesse sentido, resgata-se o desenvolvimento e a autonomia como referencial ético e político norteador de toda a prática pedagógica do Criarte. Para dar conta de tais desafios, é necessário refletir sobre os limites e as possibilidades da ação. Este trabalho buscou iniciar essa reflexão que, longe de ter uma resposta conclusiva, serviu para suscitar novas questões e horizontes. O ECMC é a busca de um sonho, a construção da autonomia e da emancipação humana.

Artigo recebido em 20 mai. 2019 Aprovado para publicação em 09 jul. 2019 


\section{Referências Bibliográficas}

ARANTES, Otília; VAINER, Carlos; MARICATO, Ermínia. A cidade do pensamento único: desmanchando consensos. Petrópolis, RJ: Vozes, 2000.

BATISTA, Luana Braga. Uma análise antropológica da representação do indígena brasileiro nos manuais didáticos de história. Trabalho de conclusão de curso (Bacharel em ciências sociais). Universidade Estadual Paulista (Unesp), Faculdade de Filosofia e Ciências Sociais, 2017.

BETTO, Frei; FREIRE, Paulo. Essa escola chamada vida: depoimentos ao repórter Ricardo Kotscho. São Pauo: Editora Ática, 1986.

BIASOTTO, Rosane. Moradia é Central: inclusão, acesso e direito a cidade. Rio de Janeiro: Instituto Polis, 2009.

BRANDÃO, Carlos Rodrigues. A cultura do povo e a educação popular. In: BRANDÃO, Carlos Rodrigues. et al. A questão política da educação popular. São Paulo: Brasiliense, 1984.

FREIRE, Paulo. Educação: o sonho possível. In: BRANDÃO, Carlos Rodrigues. org. O educador: vida e morte. Rio de Janeiro, Edições Graal, 1984.

GARCIA, Pedro Benjamim. Educação popular: algumas reflexões em torno da questão do saber. In: BRANDÃO, Carlos Rodrigues. et al. A questão política da educação popular. São Paulo: Brasiliense, 1984.

LEFEBVRE, Henri. O direito à cidade. Tradução de Rubens Eduardo Frias. São Paulo: Centauro, 2001.

MATTOS,CLG. A abordagem etnográfica na investigação científica. In: MATTOS, CLG., and CASTRO, PA., orgs, Etnografia e educação: conceitos e usos [online]. Campina Grande: EDUEPB, 2011, pp. 49-83. ISBN 978-85-7879-190-2. Available from SciELO books < http://books.scielo.org>. Acessado em 24 de junho de 2019.

MINISTÉRIO DAS CIDADES. Déficit habitacional no Brasil. Secretaria Nacional de Habitação Brasília: 2011. 140 p.

NABIL, Bonduki. Política habitacional e inclusão social no Brasil: revisão histórica e novas perspectivas no governo Lula. arq.urb Revista Eletrônica de Arquitetura e Urbanismo. São Paulo: n. 1, 2008. Disponível em:

http://www.usjt.br/arq.urb/numero 01/artigo 05 180908.pdf. Acesso em dez de 2018.

OLIVEIRA, Rosiska Darcy de; OLIVEIRA, Miguel Darcy de. A reinvenção da educação: os movimentos sociais como contexto educativo. In: FREIRE, Paulo. et al. Vivendo $e$ aprendendo: experiências do IDAC em educação popular. São Paulo: Brasiliense, 1985. 
PINI, Francisca Rodrigues de Oliveira. Educação popular e os seus diferentes espaços: educação social de rua, prisional e campo. In: IV CONGRESSO INTERNACIONAL DE PEDAGOGIA SOCIAL, 4., São Paulo, 2012. Disponível em:

http://www.proceedings.scielo.br/pdf/cips/n4v1/32.pdf. Acesso em maio de 2019. 